\title{
LETTER TO THE EDITOR (MAY 17, 2017) CONCERNING THE PAPER "IMPACT OF ROAD TRAFFIC NOISE ON SLEEP DISTURBANCES AND ATTENTION DISORDERS AMONGST SCHOOL CHILDREN LIVING IN UPPER SILESIAN INDUSTRIAL ZONE, POLAND"
}

Dear Editor,

I am very impressed by the article by Skrzypek et al. entitled "Impact of road traffic noise on sleep disturbances and attention disorders amongst school children living in Upper Silesian Industrial Zone, Poland" that was published in the "International Journal of Occupational Medicine and Environmental Health" 2017;30(3):511-20 [1]. The authors reported an association between sleep disturbances and attention disorders with exposure to road traffic noise for school children living in an urban environment. Sleep disturbances and attention disorders were judged by the parental reply to each single question. According to the multivariable logistic regression analysis, odds ratios (ORs) (95\% confidence interval (CI)) of higher traffic density for sleep disturbances and attention disorders were 1.44 (1.05-1.97) and 1.38 (1.03-1.86), respectively. I have some concerns about their study with special reference to sleep disturbance.

Firstly, I previously reviewed the effects of noise on health for children [2]. In this article, I confirmed that subjective recognition of "noisiness" was an important issue in relation to the study of noise and sleep. In addition, level of noise that influenced sleep disturbance for adults did not affect sleep for children. Furthermore, in cases of children living in noisy districts exhibiting poor academic performance, the academic performance became progressively worse as the school grade advanced. Taken together, a significant relationship between road traffic density and sleep disturbance should be confirmed by a comprehensive analysis.

Secondly, there is a gender difference in the prevalence of insomnia or sleep disturbance. Calhoun et al. reported that the prevalence of insomnia symptoms peaked for girls aged 11-12 years old [3]. They speculated that insomnia or sleep disturbance might have been related to hormonal changes, which was associated with the onset of puberty. As a half of the subjects were females, the stratified analysis by sex instead of adjusting sex as a confounder in the multivariable logistic regression analysis should also be conducted to know the effect of road traffic noise on sleep disturbance, although there was no significant association between gender and sleep disturbance in the Figure $3 \mathrm{a}$.

Finally, the definitions of sleep disturbance and attention disorders were based on the parental opinion by asking "Has the child ever had sleep disorders?" and "Has the child ever had attention disorders?," respectively. 
I suppose that validation of sleep disturbances should be paid with caution [4]. In addition, there was a discrepancy of the association among 3 indicators of traffic information. Furthermore, the content of sleep disturbance should also be considered [5]. Anyway, further studies are needed to consider the mechanism of the association.

\section{ACKNOWLEDGMENTS}

I appreciate the members of the Department of Hygiene and Public Health, Nippon Medical School, Tokyo, Japan, for their comments.

\section{Key words:}

Road traffic noise, Sleep disturbance, School children, Sex difference, Question, Risk assessment

\section{REFERENCES}

1. Skrzypek M, Kowalska M, Czech EM, Niewiadomska E, Zejda JE. Impact of road traffic noise on sleep disturbances and attention disorders amongst school children living in
Upper Silesian Industrial Zone, Poland. Int J Occup Med Environ Health. 2017;30(3):511-20, https://doi.org/10.13075/ ijomeh.1896.00823.

2. Kawada T. The effect of noise on the health of children. J Nippon Med Sch. 2004;71(1):5-10, https://doi.org/10.1272/ jnms.71.5.

3. Calhoun SL, Fernandez-Mendoza J, Vgontzas AN, Liao D, Bixler EO. Prevalence of insomnia symptoms in a general population sample of young children and preadolescents: Gender effects. Sleep Med. 2014;15(1):91-5, https://doi. org/10.1016/j.sleep.2013.08.787.

4. Rönnlund H, Elovainio M, Virtanen I, Matomäki J, Lapinleimu H. Poor parental sleep and the reported sleep quality of their children. Pediatrics. 2016;137(4):e20153425, https:// doi.org/10.1542/peds.2015-3425.

5. Evandt J, Oftedal B, Hjertager Krog N, Nafstad P, Schwarze PE, Marit Aasvang G. A population-based study on nighttime road traffic noise and insomnia. Sleep. 2017;40(2): zsw055, https://doi.org/10.1093/sleep/zsw055.

Tomoyuki Kawada

Nippon Medical School, Tokyo, Japan Department of Hygiene and Public Health

1-1-5 Sendagi, Bunkyo-Ku

Tokyo 113-8602, Japan

(e-mail:kawada@nms.ac.jp)

This work is available in Open Access model and licensed under a Creative Commons Attribution-NonCommercial 3.0 Poland License - http://creativecommons.org/ licenses/by-nc/3.0/pl/deed.en. 